Available online on 15.03.2020 at http://jddtonline.info
Open Access to Pharmaceutical and Medical Research
unrestricted non-commercial use, provided the original work is properly cited

Open Access

Research Article

\title{
Formulation, Development and Evaluation of Fast Dissolving Oral Film of a Selective Serotonin-Reuptake Inhibitor (SSRIS) Escitalopram Oxalate
}

\author{
Nitesh Yadav*, Pushpendra Soni, Lavakesh Kumar Omray \\ Radharaman Institute of Pharmaceutical Sciences, Bhopal (M.P.), India
}

\begin{abstract}
The purpose of this research was to develop fast dissolving oral film of Escitalopram oxalate. Fast dissolving oral film offers a solution for paediatrics, geriatrics; psychiatric or mentally ill people and those have difficulty in swallowing tablets/capsules resulting in improved patient compliance. Selective serotonin reuptake inhibitors (SSRIs), which are broad spectrum antidepressants that are effective for major depressive disorder and several anxiety disorders. Escitalopram Oxalate is highly selective, more effective and better than other SSRIs. The prepared formulations were evaluated for Thickness, Weight uniformity, Folding Endurance, Percentage of Moisture Content, Drug Content Analysis, Disintegrating time and In vitro dissolution study. Stability studies were carried out with optimized formulation F5 which was stored for a period of one, two and three months at $40 \pm 2^{\circ} \mathrm{C}$ temperature and $75 \pm 5 \%$ relative humidity for a period 3 months. Thus it can be concluded that Escitalopram oxalate fast dissolving films could be commercially exploited for the treatment of panic disorder using Escitalopram oxalate with merits of faster onset of action, avoidance of extensive first pass metabolism, low dosage regimen, enhanced bioavailability and improved patient compliance.
\end{abstract}

Keywords: Escitalopram oxalate, Fast dissolving oral film, Evaluation

Article Info: Received 11 Jan 2020; Review Completed 23 Feb 2020; $\quad$ Accepted March 02 2020; Available online 15 March 2020

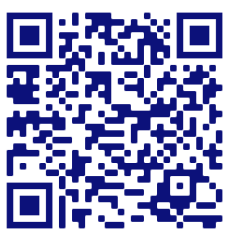

Cite this article as:

Yadav N, Soni P, Omray LK, Formulation, Development and Evaluation of Fast Dissolving Oral Film of a Selective Serotonin-Reuptake Inhibitor (SSRIS) Escitalopram Oxalate, Journal of Drug Delivery and Therapeutics. 2020; 10(2):175179 http://dx.doi.org/10.22270/jddt.v10i2.3938

Nitesh Yadav, Radharaman Institute of Pharmaceutical Sciences, Bhopal (M.P.), India

\section{INTRODUCTION}

Escitalopram oxalate is a newer antidepressant used for the treatment of panic disorder. Escitalopram oxalate is $\mathrm{S}(+)$ enantiomer of the racemic bicyclic phthalene derivative of citalopram, which is chemically $\mathrm{S}(+)-1-$ [3(dimethylamino)propyl]-1-p-flurophenyl-5-phthalene carbonitrile1-2.

Escitalopram oxalate acts by increasing intrasynaptic levels of the neurotransmitter serotonin by blocking the reuptake of the neurotransmitter into the neuron. Its half-life is about 27-32 hours. It is metabolized in the liver, especially by the CYP3A4 and CYP2C19 after oral administration. Its bioavailability is $80 \%$ and protein binding is approximately $56 \%$. It is poorly soluble in water so its absorption is less. It is acidic and its pKa value is 4.19 which is satisfactory for selection of drug. The Log Partition coefficient value is 3.45 . The tmax value of Escitalopram oxalate is $4 \mathrm{hr}$ after multiple dosing. The dose of $5-20 \mathrm{mg}$ once a day and is used for treatment of depression ${ }^{3}$.

This is seen to afflict nearly $45 \%$ of the general population. Particularly, the difficulty is experienced by pediatric and geriatric patients ${ }^{3}$. To overcome these problems, orodispersible film have been developed, which has good dose uniformity, easy administration and serves as the first choice of dosage form for pediatrics, geriatrics and travelling patients. Fast-dissolving oral films (FDFs) showed a great potential over other dosage forms for the delivery of drugs since they provide distinct advantages including rapid disintegration and dissolution in the oral cavity thus increase bioavailability with faster onset of action and avoidance of first-pass effect 4 . Due to high permeability of oral mucosa, it allows direct access of drug to the systemic circulation and avoids the first pass metabolism ${ }^{5}$. FDFs represent an advantageous dosage form, especially for geriatric and pediatric patients ${ }^{6-7}$

\section{MATERIALS AND METHODS}

\section{Materials}

Escitalopram oxalate was obtained as a gift sample from Pharmaceutical Company. HPMC was procured from Qualikems fine chem Pvt Ltd Vadodhara. PEG400, sodium starch glycolate, croscarmellose sodium was obtained from S.D fine chemicals limited, Mumbai. Citric acid, ethanol was 
obtained from Loba Chemical Pvt Ltd (Mumbai, India). Hydrochloric acid, $\mathrm{KH}_{2} \mathrm{PO}_{4}, \mathrm{NaoH}$ was obtained from S. D. Fine Chem. Ltd., Mumbai. All other chemical were purchased from Hi Media, Mumbai. Double distilled water was prepared freshly and used whenever required. All the chemicals used in this work were of analytical grade.

\section{Standardization of Escitalopram oxalate by UV-Visible spectrophotometry}

\section{Determination of $\boldsymbol{\lambda}_{\max }$ of Escitalopram oxalate}

The $\lambda_{\max }$ of Escitalopram oxalate was determined by running the spectrum of drug solution in double beam ultraviolet spectrophotometer (Labindia 3000+). Accurately weighed 10 $\mathrm{mg}$ of drug was dissolved in $10 \mathrm{ml}$ of Phosphate buffer $\mathrm{pH} 6.8$ solutions in $10 \mathrm{ml}$ of volumetric flask. The resulted solution $(1000 \mu \mathrm{g} / \mathrm{ml})$ was used to prepare the concentration $10 \mu \mathrm{g} / \mathrm{ml}$. The spectrum of this solution was recorded in $200-$ $400 \mathrm{~nm}$ range using U.V. spectrophotometer (Labindia$3000+)^{8}$. After the complete scan $\lambda_{\max }$ of Escitalopram oxalate was found $232 \mathrm{~nm}$.

\section{Preparation of calibration curve:}

From stock solutions of Escitalopram oxalate $1 \mathrm{ml}$ was taken and diluted up to $10 \mathrm{ml}$. from this solution $0.5,1.0,1.5,2.0$ and $2.5 \mathrm{ml}$ solutions were transferred to $10 \mathrm{ml}$ volumetric flasks and make up the volume up to $10 \mathrm{ml}$ with Phosphate buffer $\mathrm{pH} 6.8$, gives standard drug solution of $5,10,15,20$, $25 \mu \mathrm{g} / \mathrm{ml}$ concentration.

\section{Formulation development of oral film of Escitalopram oxalate}

\section{Solvent casting technique}

Drug (Escitalopram oxalate) containing fast dissolving films were fabricated by the solvent casting method. The optimized amount of HPMC was dissolved in $5 \mathrm{ml}$ of water and stirrer continuously for 1 hour, optimized amount of plasticizer and drug were dissolved in $95 \%$ ethanol and then added to the polymeric solution, Polymeric solution was stirred for 30 min using magnetic stirrer and was kept in undisturbed condition till the entrapped air bubbles were removed. The aqueous solution was casted in a glass moulds having $2.5 \times 2.5 \mathrm{~cm} * 10$ films area and was dried at controlled room temperature $\left(25^{\circ}-30^{\circ} \mathrm{C}, 45 \% \mathrm{RH}\right)$ as well as at increased temperature (microwave oven). The film took approximately $48 \mathrm{hr}$ to dry at controlled room temperature. The dried film was carefully removed from the glass plates and was cut into size required for testing. The films were stored in air tight plastic bags till further use. Formulations were prepared using HPMC K15, PEG-400, SSG and CCS at different drug: polymer ratios. The compositions of the formulations were shown in table 1.

Table 1: Formulation of Escitalopram oxalate oral fast dissolving films

\begin{tabular}{|l|c|c|c|c|c|c|}
\hline $\begin{array}{l}\text { Name of ingredients (mg) } \\
\text { (mg for 12 strips) }\end{array}$ & F1 & F2 & F3 & F4 & F5 & F6 \\
\hline Escitaloprám oxalate & 120 & 120 & 120 & 120 & 120 & 120 \\
\hline HPMC & 300 & 600 & 900 & 300 & 600 & 900 \\
\hline PEG-400 & 150 & 150 & 150 & 150 & 150 & 150 \\
\hline SSG & 200 & 300 & 400 & - & - & - \\
\hline CCS & - & - & - & 200 & 300 & 400 \\
\hline Mannitol & 100 & 100 & 100 & 100 & 100 & 100 \\
\hline Citric acid & 100 & 100 & 100 & 100 & 100 & 100 \\
\hline DM water qs to (ml) & 30 & 30 & 30 & 30 & 30 & 30 \\
\hline
\end{tabular}

\section{Dose calculations}

- Width of the plate $=5 \mathrm{~cm}$

- $\quad$ Length of the plate $=12 \mathrm{~cm}$

- $\quad$ No. of $2.5 \times 2.5 \mathrm{~cm}^{2}$ films present whole plate $=12$

- $\quad$ Each film contains $10 \mathrm{mg}$ of drug.

- 12 no. of films contains mg of drug? = $10 \times 12=120 \mathrm{mg}$

- The amount of Escitalopram oxalate added in each plate was approximately equal to $10 \mathrm{mg}$.

\section{Evaluation}

The formulations were evaluated by the following tests 9-12.

\section{Thickness}

Randomly 10 films were selected and thickness was measured using vernier calliper at three different places.

\section{Weight variation}

For each formulation, three randomly selected patches were used. For weight variation test, 10 films from each batch were weighed individually by digital electronic balance and the average weight was calculated.

\section{Folding endurance}

This was determined by repeatedly folding one film at the same place until it broke. The number of times the film could be folded at the same place without breaking cracking gave the value of folding endurance. 


\section{Percentage of moisture content}

The films were weighed individually and kept in desiccators containing activated silica at room temperature for $24 \mathrm{hrs}$. Individual films were weighed repeatedly until they showed a constant weight. The percentage of moisture content was calculated as the difference between initial and final weight with respect to final weight.

\section{Drug content analysis}

The patches $(\mathrm{n}=3)$ of specified area were taken into a $10 \mathrm{ml}$ volumetric flask and dissolved in methanol and volume was made up with $10 \mathrm{ml}$ methanol. Subsequent dilutions were made and analyzed by UV spectrophotometer at $232 \mathrm{~nm}$.

\section{Disintegrating time}

The most important criteria of present work are to that dosage form should be dissolved within few seconds. The incorporation of super disintegrating agent to minimizes the disintegrating time. Three super disintegrating agent were selected for this work. The film of $\left(2.5^{*} 2.5 \mathrm{~cm}\right)$ size (unit dose) was placed on a petridish containing $10 \mathrm{ml}$ of distilled water. The time required for the film to break was noted as cursive in vitro disintegration time.

\section{In vitro dissolution study}

The in vitro dissolution test was performed using the USP dissolution apparatus II (Paddle with sinker). The dissolution studies were carried out at $37 \pm 0.5^{\circ} \mathrm{C}$; with stirring speed of $50 \mathrm{rpm}$ in $900 \mathrm{ml}$ phosphate buffer ( $\mathrm{pH}$ 6.8). Film size required for dose delivery $\left(2.5 \times 2.5 \mathrm{~cm}^{2}\right)$ was used. Five $\mathrm{ml}$ aliquot of dissolution media was collected at time intervals of 1,2 and 5 minutes and replaced with equal volumes of phosphate buffer ( $\mathrm{pH}$ 6.8). The collected samples were filtered through $0.45 \mu \mathrm{m}$ membrane filter and the concentration of the dissolved Escitalopram oxalate was determined using UV-Visible spectrophotometer at $232 \mathrm{~nm}$. The results were presented as an average of three such concentrations.

\section{Stability studies}

Stability studies were carried out with optimized formulation which was stored for a period of one, two and three months at $40 \pm 2{ }^{\circ} \mathrm{C}$ temperature and $75 \pm 5 \%$ relative humidity for a period 3 months. The \% Assay of formulation was determined by U.V. spectrophotometer using calibration curve method.

\section{RESULTS AND DISCUSSION}

To check solubility of drug in other solvent like water, ethanol, methanol, $0.1 \mathrm{~N} \mathrm{HCl}, 0.1 \mathrm{~N} \mathrm{NaOH}$, Chloroform and $6.8 \mathrm{pH}$ Phosphate buffer. Melting point was determined by Melting point apparatus (Chemiline CL-725) and found to $150-151^{\circ} \mathrm{C}$. The $\lambda_{\max }$ found for Escitalopram oxalate is 232.0 $\mathrm{nm}$. Various methods are available for casting of oral films. This is fast disintegrating oral film hence on the laboratory scale solvent casting technique was adopted for formulation of films. In the present work, fast dissolving oral films of Escitalopram oxalate were prepared by solvent casting method with a view to enhance patient compliance, for the treatment of depression. Fast dissolving oral films were disintegrated in the mouth and were dissolved within a matter of few seconds without need of water. Fast dissolving oral films were prepared using different concentration of superdisintegrants and evaluated. Different formulations (F1-F6) were prepared using varying amount of SSG and CCS. The prepared formulations were evaluated for Thickness, Weight uniformity, Folding Endurance, Percentage of
Moisture Content, Drug Content Analysis, Disintegrating time and In vitro dissolution study. Stability studies were carried out with optimized formulation F5 which was stored for a period of one, two and three months at $40 \pm 2{ }^{\circ} \mathrm{C}$ temperature and $75 \pm 5 \%$ relative humidity for a period 3 months. The $\%$ Assay of formulation was determined by U.V. spectrophotometer using calibration curve method. The \% assay of film was found to slightly decrease at higher temperature.

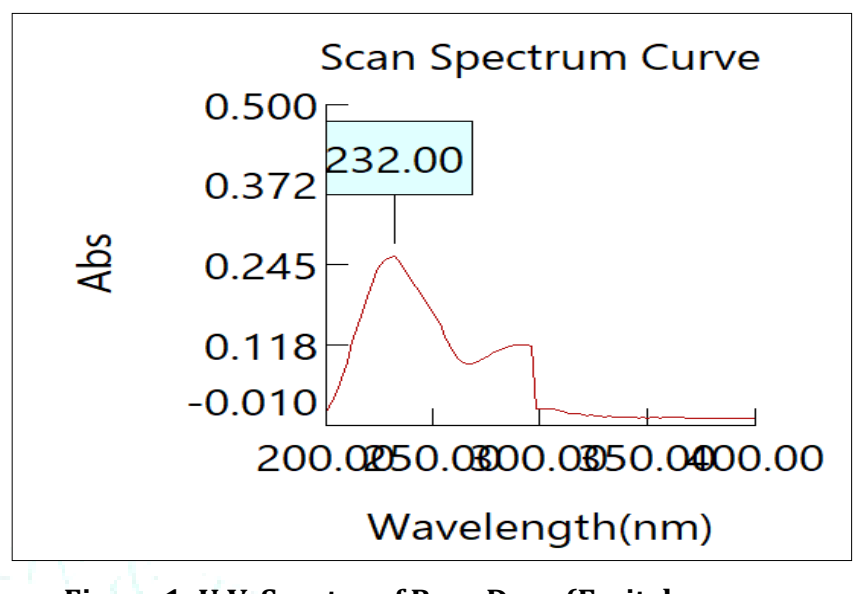

Figure 1: U.V. Spectra of Pure Drug (Escitalopram oxalate)

G) Calibration curve of Escitalopram oxalate at $\lambda$ max 232nm

Observation table:

Table 2: Calibration curve of Escitalopram oxalate in Phosphate buffer pH 6.8

\begin{tabular}{|c|c|c|}
\hline S. No. & Conc. $(\boldsymbol{\mu g} / \mathbf{m l})$ & Absorbance \\
\hline $\mathbf{1 .}$ & 2 & 0.207 \\
\hline $\mathbf{2 .}$ & 4 & 0.378 \\
\hline $\mathbf{3 .}$ & 6 & 0.534 \\
\hline $\mathbf{4 .}$ & 8 & 0.685 \\
\hline $\mathbf{5 .}$ & 10 & 0.871 \\
\hline
\end{tabular}

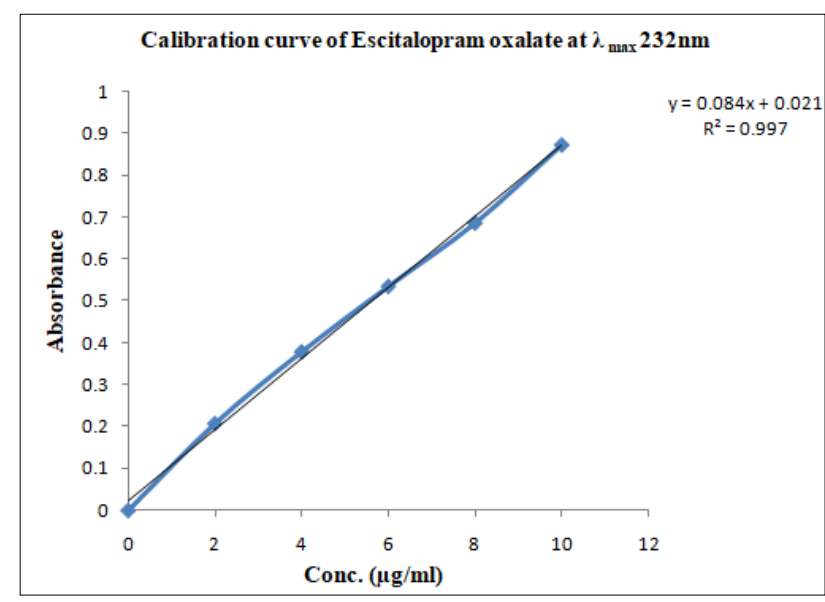

Figure 2: Calibration Curve of Escitalopram oxalate in Phosphate buffer pH 6.8 at $232 \mathrm{~nm}$ 
Table 3: Result of general appearance, thickness, weight variation and \% assay

\begin{tabular}{|c|c|c|c|c|}
\hline Formulation code & $\begin{array}{c}\text { General } \\
\text { Appearance }\end{array}$ & $\begin{array}{c}\text { Thickness* } \\
\mathbf{(} \boldsymbol{\mu m})\end{array}$ & $\begin{array}{c}\text { Weight* } \\
\mathbf{( m g )}\end{array}$ & (\%) Assay* \\
\hline F1 & Translucent & $0.09 \pm 0.01$ & 85 & $96.65 \pm 0.12$ \\
\hline F2 & Translucent & $0.10 \pm 0.02$ & 122 & $97.56 \pm 0.21$ \\
\hline F3 & Translucent & $0.12 \pm 0.02$ & 153 & $96.45 \pm 0.14$ \\
\hline F4 & Translucent & $0.08 \pm 0.01$ & 86 & $97.45 \pm 0.32$ \\
\hline F5 & Translucent & $0.12 \pm 0.02$ & 125 & $99.85 \pm 0.14$ \\
\hline F6 & Translucent & $0.13 \pm 0.02$ & 155 & $98.85 \pm 0.25$ \\
\hline
\end{tabular}

*Average of three determination $(\mathrm{n}=3)$

Table 4: Result of folding endurance, disintegrating time, tensile strength $\& \%$ of moisture content

\begin{tabular}{|c|c|c|c|c|}
\hline $\begin{array}{c}\text { Formulation } \\
\text { code }\end{array}$ & $\begin{array}{c}\text { Folding } \\
\text { endurance* }\end{array}$ & $\begin{array}{c}\text { Disintegration } \\
\text { time (Sec.)* }\end{array}$ & $\begin{array}{c}\text { Tensile strength } \\
\left(\mathrm{kg} / \mathrm{cm}^{2}\right)^{*}\end{array}$ & $\begin{array}{c}\text { Moisture Content } \\
(\%)^{*}\end{array}$ \\
\hline F1 & More than 100 & $88 \pm 4$ & $0.658 \pm 0.008$ & $2.23 \pm 0.12$ \\
\hline F2 & More than 100 & $80 \pm 5$ & $0.698 \pm 0.006$ & $2.10 \pm 0.14$ \\
\hline F3 & More than 100 & $73 \pm 3$ & $0.712 \pm 0.007$ & $1.85 \pm 013$ \\
\hline F4 & More than 100 & $66 \pm 5$ & $0.612 \pm 0.006$ & $1.65 \pm 14$ \\
\hline F5 & More than 100 & $50 \pm 4$ & $0.756 \pm 0.005$ & $1.21 \pm 12$ \\
\hline F6 & More than 100 & $60 \pm 5$ & $0.763 \pm 0.004$ & $1.92 \pm 11$ \\
\hline
\end{tabular}

*Average of three determination $(\mathrm{n}=3)$

Table 5: Results of In-Vitro release study of optimized formulation F3

\begin{tabular}{|c|c|c|}
\hline S. No. & Time (Min.) & Cumulative \% Drug release \\
\hline 1. & 1 & $33.45 \pm 0.45$ \\
\hline 2. & 2 & $67.85 \pm 0.65$ \\
\hline 3. & 5 & $96.65 \pm 0.32$ \\
\hline
\end{tabular}

Table 6: Characterization of stability study of optimized film (F3)

\begin{tabular}{|c|c|c|c|c|}
\hline \multirow{2}{*}{ Characteristic } & \multicolumn{4}{|c|}{ Time (Month) } \\
\cline { 2 - 5 } & Initial & 1 Month & 2 Month & 3 Month \\
\hline \% Assay* & $99.12 \pm 0.45$ & $98.45 \pm 0.32$ & $98.12 \pm 0.45$ & $98.05 \pm 0.65$ \\
\hline
\end{tabular}

\section{CONCLUSION}

Fast dissolving oral films were prepared using different concentration of superdisintegrants and evaluated. Different formulations (F1-F6) were prepared using varying amount of SSG and CCS. The prepared formulations were evaluated for thickness, weight uniformity, folding endurance, percentage of moisture content, drug content analysis, disintegrating time and In vitro dissolution study. Stability studies were carried out with optimized formulation F5 which was stored for a period of one, two and three months at $40 \pm 2{ }^{\circ} \mathrm{C}$ temperature and $75 \pm 5 \%$ relative humidity for a period 3 months. The $\%$ Assay of formulation was determined by U.V. spectrophotometer using calibration curve method. The $\%$ assay of film was found to slightly decrease at higher temperature. Results of evaluation parameters of optimized and validated Escitalopram oxalate oral fast dissolving films revealed good mechanical strength, uniformity of content, optimum surface $\mathrm{pH}$, faster disintegration time, almost complete drug dissolution or release and good stability up to three months. Thus it can be concluded that Escitalopram oxalate fast dissolving films could be commercially exploited for the treatment of panic disorder using Escitalopram oxalate with merits of faster onset of action, avoidance of extensive first pass metabolism, low dosage regimen, enhanced bioavailability and improved patient compliance. 


\section{ACKNOWLEDGMENTS}

The authors would like to thank the Mr. Prabhat Kumar Jain, Geeta Parkhe and all supporting staff of Scan Research Laboratories, Bhopal (M.P.) who helped in the experiments during research work.

\section{REFERENCES}

1. Current Index of Medical Specialties. Bangalore: MP Medica Pvt Ltd. 2007; 99:211.

2. Baldessarini RJ. Drugs and the treatment of psychiatric disorders: Depression and anxiety disorders. In: Hardman JG, Limbird LE, Gilman AG, editors. Goodman and Gilman's The Pharmacological Basis of Therapeutics. 10 $0^{\text {th }}$ ed. London: McGraw-Hill. 2001; 457.

3. Chand P, Gnanarajan G, Kumar G, Kothiyal P. Formulation and evaluation of nasal in-situ gel of escitalopram oxalate for treatment of depression. Eur J Biomed Pharm Sci. 2016; 3(8): 185-201.

4. Figueroa LS, Bhakay A, Jackeline I, Rozo J, Pandya N, Romanach RJ, et al. Preparation and characterization of hydroxyl propyl methyl cellulose films containing stable BCS class II drug nanoparticles for pharmaceutical applications. Int J Pharm. 2012; 423:496-508.

5. Chaudhary H, Gauri S, Rathee P, Kumar V. Development and optimization of fast dissolving oro-dispersible films of
Granisetron $\mathrm{HCl}$ using box-behnken statistical design. Bull Faculty Pharm 2013; 51:193-201.

6. Choudhary DR, Patel VA, Chhalotiya UK, Patel HV, Kundawala AJ Development and characterization of pharmacokinetic parameters of fast dissolving films containing levocetirizine. Sci Pharm. 2012; 80:779-87.

7. Cilurzo F, Cupone IE, Minghetti P, Buratti S, Selmin F, Gennari CG, et al. Nicotine fast dissolving films made of maltodextrins: A feasibility study. AAPS J. 2010; 11:1511-7.

8. Narware H, Malviya K, Sirohi B, Omray LK. RP-HPLC and UV spectrophotometric methods for estimation of ticagrelor in pharmaceutical formulations. Asian Journal of Pharmaceutical Education and Research. 2018; 7(4): 94-106.

9. Singh J, Choubey N, Sharma HK, Budholiya P, Parkhe G. Journal of Medical Pharmaceutical and Allied Sciences. 2019; 8(5): 2347 2358.

10. Khan MA, Pandey GK, Joshi A, Dubey BK, Jain AK, Jain P. Formulation development and evaluation of fast dissolving oral film of a lipid-lowering drug. Asian Journal of Pharmaceutical Education and Research. 2019; 8(1): 12-22.

11. Sahu G, Patel M, Jain P, Pandey A. Formulation and evaluation of fast dissolving oral films of trazodone hydrochloride. Asian Journal of Pharmaceutical Education and Research. 2018, $7(4): 30-38$.

12. Patle B, Jain V, Shende S, Jain PK. Formulation Development and Evaluation of Sustain Release Gastroretentive Floating Tablets of Prochlorperazine Dimaleate. JDDT. 2019; 9(4):445-50. 